\title{
PRÁTICAS EDUCATIVAS EM SAÚDE: DA FUNDAMENTAÇÃO À CONSTRUÇÃO DE UMA DISCIPLINA CURRICULAR
}

\author{
Educational practice in health area: from the base to the \\ construction of a curricular subject \\ Prácticas educativas en la salud: del fundamento a la \\ construcción de una asignatura
}

\author{
Maria Helena Salgado Bagnato ${ }^{1}$ \\ Rogério Dias Renovato ${ }^{3}$
}

Lourdes Missio²

Greicelene Aparecida Hespanhol Bassinello ${ }^{4}$

\begin{abstract}
RESUMO
Este trabalho procura apresentar o processo de construção da disciplina Práticas Educativas em Saúde, introduzida no currículo implantado em 2006 e desenvolvida no Curso de Licenciatura em Enfermagem da Universidade Estadual de Campinas, Campinas, SP. 0 percurso desse trabalho passou pelas tentativas de aproximação entre a educação e a saúde e os aportes dos estudos culturais, atravessando esses campos disciplinares, sem perder o fio condutor de outras possibilidades para a construção do saber pedagógico na formação do enfermeiro. No decorrer da disciplina, foram abordados tópicos importantes, como as concepções de ser humano, de corpo, de saúde, a relação educação-saúde, dentre outros. Neste contexto, estabeleceram-se interlocuções com referenciais que movimentaram os paradigmas, os discursos e as práticas em saúde. Assim, nossa trajetória no pleito da disciplina possibilitou compreender a historicidade das práticas educativas em saúde e os pressupostos que as têm orientado para subsidiar análises críticas no desenvolvimento dessas práticas.
\end{abstract}

Palavras-chave: Educação em Saúde. Cultura. Enfermagem. Saúde.

\begin{abstract}
This work presents the process of building a subject named Educational Practice in Health Area, which has become part of the curricular program since 2006 and has been developed in the Nursing course in Campinas University, Campinas, SP. This study was accomplished by trying to put together Education, Health and Cultural Studies, going through these fields and keeping them connected to other possibilities of building up the pedagogical knowledge for the graduating nurse. During the classes important topics were discussed, such as conceptions of the human being, of the body, health, the education-health relation, among others. In this context, interlocutions were established to shake the paradigms, the speeches and the practice in Health Area. Hence, our trajectory towards the discipline enabled us to understand the historicity of Educational Practice in Health Area and the purposes that have guided them to support critical analysis in developing those practices.
\end{abstract}

Key words: Health Education. Culture. Nursing. Health.

\section{Resumen}

Este trabajo busca presentar el proceso de construcción de la asignatura de Prácticas Educativas en la Salud, introducida en el curriculum implantado en 2006 y desarrollado en el Curso de Licenciatura en Enfermería de la Universidad Estatal de Campinas, Campinas, SP. El recorrido del presente trabajo pretende hacer una aproximación entre la Educación y Salud y los fundamentos de los Estudios Culturales, entrecruzando estos campos, sin perder el hilo conductor de otras posibilidades para la construcción del saber pedagógico en la formación del Enfermero(a). Durante el desarrollo de la asignatura, fueron abordados importantes temas como la concepción de ser humano, de cuerpo, de salud, la conexión entre la educación y la salud, entre otros. En este contexto, se establecieron interlocuciones con referenciales que movilizaron paradigmas, discursos y prácticas en salud De esta forma, nuestra trayectoria en la construcción de la asignatura, posibilitó la comprensión de la historicidad de las Prácticas Educativas en la Salud y los presupuestos que han orientado el análisis crítico del I desarrollo de estas prácticas.

Palabras Clave: Educación en Salud. Cultura. Enfermería. Salud.

\footnotetext{
'Enfermeira. Brasileira. Professora Livre-docente da Faculdade de Educação da Universidade Estadual de Campinas - UNICAMP. Pós-Doutorado em Educação pela Universidade de Barcelona. Coordenadora do Laboratório de Práticas de Educação e Saúde - PRAESA/FE/UNICAMP. Campinas/SP. Brasil. E-mail: mbagnato@unicamp.br, ²Enfermeira. Brasileira. Doutora em Educação pela UNICAMP. Docente da Universidade Estadual de Mato Grosso do Sul/ UEMS. Dourados/MS. Membro do Laboratório de Práticas de Educação e Saúde - PRAESA/FE/UNICAMP. Brasil. E-mail: lourdesmissio@uems.br, ${ }^{3}$ Farmacêutico. Brasileiro. Doutorando em Educação da Faculdade de Educação da UNICAMP. Docente da Universidade Estadual de Mato Grosso do Sul/ UEMS. Dourados/MS. Membro do Laboratório de Práticas de Educação e Saúde - PRAESA/FE/UNICAMP. Brasil. E-mail: rrenovato@uol.com.br, ${ }^{4}$ Enfermeira. Brasileira. Doutora em Educação. Docente das Faculdades Integradas Einstein de Limeira - FIEL/Limeira/ São Paulo. Enfermeira da Secretaria de Estado da Saúde de São Paulo - DRS X. Membro do Laboratório de Práticas de Educação e Saúde - PRAESA/FE/UNICAMP. Brasil. E-mail: ilabas@terra.com.br.
} 
Práticas Educativas em Saúde: disciplina curricular Bagnato MHS, Missio L, Renovato RD, Bassinello GAH

\section{INTRODUCÃO}

0 presente texto procura apresentar a construção da disciplina Práticas Educativas em Saúde - PES, desenvolvida em 2007 no Curso de Licenciatura em Enfermagem da Universidade Estadual de Campinas (UNICAMP).

A disciplina foi introduzida no segundo semestre do currículo implantado em 2006, tendo como proposta discutir as PES em suas diferentes dimensões e espaços. Para tanto, consideramos as implicações dos contextos sociais, históricos e culturais e as possibilidades de estabelecer interlocuç̃es com referenciais que movimentem os paradigmas e as práticas em saúde, pretendendo que estes espaços sejam férteis para avançar no trabalho de educação e saúde como práticas sociais articuladas e contributivas de uma organização social mais justa e equânime.

Tendo como fundamentação teórica os aportes dos Estudos Culturais (EC) - referencial ainda pouco explorado na área da saúde - no decorrer da disciplina foram abordados tópicos importantes para a formação do enfermeiro, como as concepções de ser humano, de corpo, de saúde, a relação educação-saúde, as mediações dos artefatos culturais, os conceitos de discurso, as relações de poder-saber, o biopoder e seus deslocamentos.

\section{SITUANDO PRÁTICAS EDUCATIVAS EM SAÚDE}

Entendemos que as práticas educativas em saúde podem envolver trabalhos junto a famílias, grupos, usuários e trabalhadores da área da saúde, assim como a educação inicial em saúde nos cursos de nível médio e superior, e a educação continuada em saúde, como os cursos de atualização e de pósgraduação. ${ }^{1}$

São práticas que circulam nos mais variados espaços e atingem a nossa cotidianidade, em que se percebem discursos sobre a saúde, sobre o corpo e comportamentos, ou a crença ainda presente de que os problemas da falta de saúde estão interligados à carência de informações técnico-científicas e à necessidade de alguém (autoridade) capaz de ensinar, orientar e educar como cada indivíduo deve proceder para ter saúde, disciplinando e homogeneizando condutas. ${ }^{2}$

Desse modo, as PES podem se constituir em dispositivos meramente informacionais acerca da saúde, que têm a finalidade de mudar comportamentos das pessoas, produzindo normas e reforçando a culpabilização. Sob essa perspectiva, 0 problema da falta de saúde é transferido para o outro, aquele que não se cuida e age diferentemente das prescrições emitidas pelos discursos sobre educação em saúde.

Todavia, esse processo de individualização parece desconsiderar que estamos imersos em um sistema socioeconômico permeado de exclusão, e que impede 0 exercício da cidadania, nos seus modos de pensar, expressar e ser. Os processos de assimetria parecem se manter nesse mosaico de culturas diferentes, de distintos códigos linguísticos, potencializando as desigualdades e deixando à margem o outro.
Em relação às $P E S$, as tensões e reações aos modelos de homogeneização também se materializam. Ao longo dos tempos históricos, encontramos tentativas de moldar, docilizar e disciplinar homens e mulheres. Para isso, o campo da saúde tornou-se palco de relações de poder, tentativas de delimitar modelos de cidadania, e assim disseminar modos de entender a saúde, como manter o corpo saudável por meio de estratégias cuja posse do saber instituído seria elemento suficiente para se promover uma vida com saúde.

Todavia, na contemporaneidade, os processos de individualização avançam nas sociedades neoliberais, repercutindo em ações corrosivas da cidadania e na ilusória liberdade de que o cidadão pode fazer suas escolhas. Para Bagnato $^{2: 178}$, ao priorizar em todos os espaços o próprio indivíduo, acaba-se esvaziando os espaços públicos - nessa situação, o privado coloniza o público. Por sua vez, nesse processo não há a quem culpar pela própria miséria, não há por que buscar as causas da derrota, é em si que há que se procurar saídas.

Em outro aspecto, percebemos a redução do corpo e da própria saúde à lógica do mercado, em tentativas de persuasão mediadas pelo discurso midiático, dando relevância a modelos clínicos e estéticos restritos. Logo, existem riscos evidentes de que as PES podem contribuir e reforçar o ideário do novo higienismo, por meio de técnicas de convencimento e sedução.

Assim, nossa proposta na construção dessa disciplina, e sua aproximação com os EC, teve como elemento norteador a reciprocidade dialógica. Nesta perspectiva, procuramos trabalhar com as diferenças (não a homogeneização), consideramos que não existe neutralidade nos discursos educativos em saúde, mas que pode se conviver com as outras maneiras de olhar, de compreender os vários significados da saúde e da vida. Ou seja:

As PES podem se constituir em espaços de encontros com o(s) outro(s), sujeito(s) portador(es) de diferentes saberes, experiências, representações, culturas, lugares sociais, valores, necessidades, experiências cotidianas, práticas sociais; também são espaços de vivências, de produção de subjetividades, de sentidos e significados que vão sendo construídos e desconstruídos em um tempo e espaço históricos. ${ }^{1: 98}$

\section{CONSTRUINDO A DISCIPLINA}

A disciplina Práticas Educativas em Saúde teve como objetivo situar e compreender as PES nos diferentes cenários sócio-histórico-culturais em suas múltiplas manifestações. Neste contexto, estabelecemos interlocuções com referenciais que movimentassem os paradigmas, os discursos e as práticas em saúde, pretendendo que estes espaços fossem férteis para ampliar a participação e a democratização destas práticas na sociedade.

Como percurso metodológico, os objetivos específicos da disciplina pretendiam compreender a historicidade das PES e os pressupostos que as têm orientado para subsidiar análises 
Práticas Educativas em Saúde: disciplina curricular Bagnato MHS, Missio L, Renovato RD, Bassinello GAH

críticas das influências sociais, políticas e culturais no desenvolvimento das práticas educativas em saúde.

Desta forma, buscamos propiciar o contato dos sujeitos educativos/acadêmicos provenientes de diferentes espaços, lugares e culturas, trazendo ao curso singularidades específicas de suas vivências e etapas de formação com as PES, para observar situações reais e diversificadas destas atividades em instituições de educação e de saúde. Assim, elaboramos um roteiro para visita ao campo, com divisão dos sujeitos educativos em grupos e a delimitação dos locais a serem visitados.

Para o planejamento das ações educativas, discutimos aportes teóricos, políticos e éticos para a proposição de práticas e de avaliação educativas inovadoras, problematizando o papel dos sujeitos educativos e a relevância do trabalho coletivo.

No desenvolvimento da disciplina, tivemos como proposta socializar as experiências das PES, por meio de exposições dialogadas dos conteúdos; das leituras individuais e coletivas de textos seguidas de discussões; de realização de trabalhos em grupos; de observação e implementação de PES em diferentes espaços.

Desta maneira, escolhemos três unidades para a construção do conteúdo programático: Educação, saúde e sociedade (Unidade I); Aportes teóricos metodológicos em debate: movimentando conceitos e aportes nas PES (Unidade II); e Implementando PES (Unidade III).

Na Unidade I, procuramos contextualizar as PES, cotejandoas com a teimosia do modelo de saúde disciplinador/ normatizador. Para tanto, foi importante explicitarmos nossa compreensão da História, cenários e sujeitos das PES, bem como a pluralidade de espaços, tempos e atores e teias de relações: subjetivas, interativas e contextuais.

Na Unidade II, trabalhamos a análise da fundamentação teórico-metodológica como a Educação Crítica e a Abordagem Dialética e a problematização, a Educação Popular em Saúde, buscando situar o universo epistemológico destas propostas com 0 aporte dos EC, bem como verificar quais as suas contribuiç̃̃es para as PES.

Realizamos reflexões envolvendo outros olhares sobre as práticas, beneficiando-nos de novos caminhos, como o diálogo com os EC e as concepções intencionalmente construídas sobre o ser humano, a saúde e o corpo, articulando com outros elementos provenientes do olhar foucaultiano, como o discurso, relações de poder-saber-sujeito, efeitos de verdade e biopoder.

Na Unidade III, refletimos sobre os trabalhos realizados pelos acadêmicos, caracterizando-os e analisando as experiências vivenciadas. Interessou-nos configurar quantas e quais foram as experiências elencadas, considerando os aspectos teórico-metodológico; qual a abrangência desses trabalhos; como eles se organizaram; os pressupostos que the deram suporte e os conhecimentos produzidos, seus sentidos e significados.

0 uso de diversos artefatos culturais (poemas, músicas, imagens, filmes, jornais, danças, grafite, etc) e suas respectivas linguagens-discursos nas PES foram problematizados, buscando explicitar seu caráter ideológico, de produtores de sentidos e significados, na sociedade atual, incluindo os modos de ser, estar e viver saúde.

Na disciplina Práticas Educativas em Saúde, assumimos a concepção de discurso com um sentido similar ao de linguagem e narrativa, significando instâncias instituidoras de representaç̃̃es, de significados que vigoram e têm efeitos de verdade. $^{2}$

A avaliação da disciplina ocorreu de forma processual e constou de leitura de textos, participação nos debates, dinâmicas e apresentações da turma (poemas e danças), entrega dos trabalhos escritos e o desenvolvimento de PES com seus respectivos relatórios.

\section{CONHECENDO A FUNDAMENTAÇÃO TEÓRICA}

0 campo dos EC tem servido de arcabouço teórico para pesquisas e discussões, envolvendo as mais diversas formas de produções nas várias áreas do conhecimento (educação, saúde, sociologia, antropologia, dentre outras).

Os EC surgiram na Inglaterra nos anos 50 tendo como finalidade analisar as relações entre a cultura contemporânea e a sociedade, isto é, suas formas culturais, instituições e práticas culturais, assim como suas relações com a sociedade e as mudanças sociais. ${ }^{3}$

Desde suas origens e ao longo de uma trajetória de consolidação e expansão, os EC, por meio de teóricos como Richard Hoggart, Edward Palmer Thompson, Raymond Williams, apresentaram como eixo central em suas produções bibliográficas importantes modificações sobre a concepção de cultura, extrapolando os domínios estético e humanístico, e abrindo possibilidades de outras leituras. ${ }^{3,5}$

Assim, o estudo da cultura passou a não se limitar apenas às produções e artefatos reconhecidos como 'elitistas', contemplando também as consideradas 'ordinárias' e presentes nas múltiplas práticas sociais. Os EC apresentaram forte influência marxista; no entanto, não aceitaram o fato de que a cultura foi condicionada pelo reducionismo economicista, mas se constituiu em território de lutas e relações de poder., ${ }^{6,7}$

Os EC apresentam projetos de abordagens com perspectivas críticas e multidisciplinares. Utilizam-se de quaisquer campos que forem necessários para produzir o conhecimento exigido por um projeto particular. Têm como finalidade analisar as relações entre a cultura contemporânea e a sociedade, isto é, suas formas culturais, instituições e práticas culturais, assim como suas relações com a sociedade e as mudanças sociais. ${ }^{3}$ Segundo Escosteguy ${ }^{3}$, os EC devem ser vistos tanto do ponto de vista político, na tentativa de construção de um projeto político, como do ponto de vista teórico, ou seja, com a perspectiva de organizar um novo campo de estudos. Os EC, como campo epistemológico, percorrem territórios do saber e, por meio da bricolage, articulam e constroem novos conhecimentos na interface das relações entre sociedade e a cultura. 
Práticas Educativas em Saúde: disciplina curricular Bagnato MHS, Missio L, Renovato RD, Bassinello GAH

Assim, sob esta perspectiva, é possível tecer outras compreensões sobre os discursos transmitidos por artefatos culturais, como os jornais, livros, televisão, internet e até artigos científicos, que funcionam como mecanismos de representações e, ao mesmo tempo, operam como constituidores de identidades. $^{2}$

A aproximação dos campos da educação e da saúde expressa a potencialidade dos EC como "teoria viajante", admitindo sua vocação para transitar por variados universos simbólicos e culturais. É a teoria que viaja mais.

No campo da educação, verificamos muitas produções nacionais acadêmicas que procuram tecer articulações com os EC. Dentre esses exemplos estão aqueles citados por Costa et al..$^{4}$ Contudo, na área da saúde, o diálogo com os EC ainda é incipiente, porém já encontramos algumas produções bibliográficas, como teses, artigos e livros, sobre essa temática. ${ }^{8,11}$

Os EC pretendem analisar os elos entre a cultura contemporânea e as mudanças sociais, oferecendo a possibilidade de criar espaços de movimentação e promover rupturas nos modos hegemônicos de explicar os fenômenos. Logo, os EC nos convidam a examinar as diversas maneiras de pensar e compreender as práticas do cotidiano, propondo um olhar interdisciplinar, que entende os processos culturais como inter-relacionados, e não como fenômenos isolados. ${ }^{2}$

Desta forma, acreditamos que os EC podem contribuir na formação profissional para a área da saúde e da educação, por se tratar de um aporte pouco explorado na área da saúde, resgatando a perspectiva interdisciplinar, pondo em diálogo diferentes linguagens e concepções, oferecendo múltiplas leituras e possibilitando um contraponto ao discurso dominante nesta área, como por exemplo, a neutralidade e a onipotência pretensiosa dos discursos científicos.

\section{MOVIMENTANDO CONCEPÇÕES}

Para auxiliar na construção da disciplina Práticas Educativas em Saúde, elegemos algumas concepções e teorizações sobre ser humano, saúde, corpo e educação em saúde, procurando conduzir esse percurso, não como as coisas em si, mas como produtos do discurso que se movimentam e se transformam, envoltos em vários jogos de poder.

Desta forma, nas práticas educativas em saúde, seria mais produtivo compreender o ser humano englobando os aspectos sociais, históricos e culturais, entendendo-o em suas múltiplas manifestações, como: o homem ético de Sócrates, o homem racional de Descartes, o homem simbólico de Cassirer, o homem universal de Kant, o homem matéria de Marx, o homem fragmentado de Hall, e, com o refinamento e a penetração do mundo da produção em todas as esferas da vida, consideramos possível falar também do homem consumidor. Essas concepções de ser humano emergem no processo educativo. ${ }^{1}$

Para Bagnato e Renovato ${ }^{1: 94}$, o ser humano é um sujeito que:
(...) se constitui nas relações consigo mesmo, com outras pessoas, com os meios de comunicação, com grupos religiosos, com famílias, com os conhecimentos a que tem acesso, com lugares que vai ocupando. O conhecimento do outro é construído e desconstruído no diálogo, na diversidade de vozes, através de palavras, gestos e ações.

Neste sentido, entendemos que os EC podem trazer outros contrapontos para além do predomínio do modelo biomédico nas práticas educativas, abrindo-se às outras referências do saber, entendendo que os seres humanos - sujeitos desta prática, que prestam e recebem cuidados - são seres multirreferenciais, seres históricos, sociais, políticos e culturais.

Em relação ao conceito sobre saúde, partimos do conceito de hibridização de Canclini $^{12}$, entendendo que a compreensão de saúde provém de outras margens e intersecções, confluindo para a desterritorização de processos simbólicos, e produzindo a mescla de vários campos do saber, em que a racionalidade médica é uma das possibilidades. Assim, a saúde envolve um emaranhado de elementos discursivos que se constituem no cotidiano e circulam componentes dos saberes da ciência, da cultura, da economia e da política, bem como as experiências vivenciadas pelo ser humano em espaços e tempos historicamente singulares.

Sobre a compreensão de corpo, compartilhamos do questionamento de Santos ${ }^{11}$ cuja noção se encontra na fronteira do biológico e do cultural, pois é nesta intersecção, entre aquilo que recebemos como herança biológica e o que nos é dado como herança cultural, que construímos as representações que constituem o acesso aos nossos corpos.

Segundo o mesmo autor, com esse entendimento, o corpo não pode ser visto apenas como biologia e nem somente como cultura. Para ele, o corpo "é resultado desta interação: um corpo singular que não se reproduz (não produz cópias, clones de si) e, como híbrido, precisa sempre dos dois. Biologia e cultura se hibridizam e constituem um corpo humano". ${ }^{11: 7}$

Acerca das relações educação-saúde, poder-saber e biopoder, buscamos delinear outros olhares e movimentos que potencializam leituras pouco exploradas nas temáticas relacionadas à educação e saúde, importantes para a formação do enfermeiro.

Atualmente, as propostas para a educação em saúde têm se fundamentado em conceitos que apregoam a autonomia do sujeito, sua participação e agenciamento como autor de suas próprias escolhas. A possibilidade de se aplicar métodos, táticas e estratégias para estimular o auto-governo, o gerenciamento de si e o cuidado de si parecem predominar nas articulações entre a educação em saúde e a promoção em saúde. A educação se constitui como um processo de formação, mediada pelas experiências, por valores, atitudes, conhecimentos e práticas, considerando o ser humano como sujeito histórico com possibilidades de intervir na realidade. 
Para muitos teóricos, a educação em saúde é um dos percursos pelo qual o ser humano pode exercitar sua cidadania, alcançar sua plenitude, principalmente em um mundo em que a saúde e a qualidade de vida alcançaram papel relevante na constituição do "self". 0 papel da educação em saúde alicerçado sob a hegemonia da biomedicina traz consigo ainda a ideia de emancipação da humanidade. Assim, os sujeitos ou seres humanos são carentes de conhecimento, e, portanto, o papel do educador em saúde é transformá-los em cidadãos esclarecidos, senhores de seu próprio corpo e saúde, sob contínua vigilância e autocuidado.

Esses sujeitos assumem, então, o papel de administradores eficazes e eficientes de seus corpos, dirimindo quaisquer possibilidades de desvio das tênues normas e padrões determinados pelo saber científico e socializados por meio de protocolos e diretrizes de instituições e especialistas, cuja autoridade é outorgada pela sociedade.

Como um dos fios condutores dessa reflexão, percebemos que as práticas educativas em saúde contemporâneas podem ser compreendidas a partir dos desdobramentos do biopoder, bem como os discursos sobre o sujeito autônomo. Para Bagnato e Renovato ${ }^{1}$, as concepções de saúde, educação e ser humano assumiram contornos variados, que se prestaram muito mais para regular, controlar e disciplinar homens e mulheres, para cer to modelo de sociedade. Assim, o governo sobre a vida, 0 controle sobre os corpos e a vigilância pela medicina social contribuíram na constituição de um sujeito disciplinado, como relata Foucault. ${ }^{13}$

$\mathrm{Na}$ atualidade, as PES estão permeadas de elementos discursivos, que enfatizam os cuidados do corpo, os cuidados médicos, higiênicos e estéticos, compondo e redimensionando as identidades. Assim, as PES podem ser asceses contemporâneas, estabelecem novos valores, novos critérios, com base em regras de desempenho físico e de fabricação de padrões artificiais. Contudo, a homogeneização e a individualização, como características do conceito clássico de biopoder, permanecem nessas tentativas de controle sobre 0 corpo. Assim, entendemos que as PES podem ser as práticas de bioascese, ao promoverem o deslocamento de um tipo de subjetividade para outro tipo, pautados sob o discurso do risco, cujo fim maior é o corpo. ${ }^{14}$

Neste sentido, chamamos a atenção às tentativas em conduzir a conduta do outro e como isso pode interferir e interfere na construção das subjetividades, marginalizando aqueles que não se encaixam nos padrões de saúde atuais. Se a educação em saúde, no decorrer do século XX e até hoje, apresenta elementos do poder disciplinar, verificamos também a inserção de um ethos, que privilegia mais ainda o indivíduo, desconsidera o social e promove a homogeneização. ${ }^{15}$

Por fim, para Figueiredo et al., as práticas educativas em saúde não requerem apenas a capacitação para as práticas do (auto)cuidado, mas o desenvolvimento de conhecimentos, habilidades e atitudes positivas a partir do trabalho crítico- reflexivo dos direitos e deveres próprios da cidadania que leva os sujeitos a uma conscientização e reflexão e possibilita mudança de comportamento. ${ }^{16}$

\section{SINTETIZANDO A EXPERIÊNCIA}

0 percurso desse trabalho passou pelas tentativas de aproximação entre a educação e saúde e os EC, atravessando esses campos disciplinares, sem perder o fio condutor de outras possibilidades para a construção do saber pedagógico na formação do enfermeiro.

A disciplina Práticas Educativas em Saúde procurou situar e compreender as PES nos diferentes cenários sócio-históricoculturais em suas múltiplas manifestações. Neste contexto, estabeleceu interlocuções com referenciais que movimentaram os paradigmas, os discursos e as práticas em saúde, pretendendo problematizar os efeitos de verdade construídos historicamente em tessituras de descontinuidade nas sociedades. Assim, nossa trajetória no pleito da disciplina possibilitou compreender a historicidade das PES e os pressupostos que as têm orientado para subsidiar análises críticas das influências contextuais e locais no desenvolvimento dessas práticas.

Desta forma, buscamos propiciar o contato dos sujeitos educativos/acadêmicos provenientes de diferentes espaços, lugares e culturas com esse território de saberes e entremeados de relações de poder, para observar situações reais e diversificadas destas atividades em instituições de educação e de saúde. Como estratégia metodológica, elaboramos idas aos campos de práticas, organizadas em grupos sob a tutoria dos docentes e enfermeiros responsáveis pelos serviços, além de exposições dialogadas dos conteúdos, de leituras individuais e compartilhadas de textos seguidas de discussões e a realização de trabalhos em grupos.

Assim, ao longo desse percurso, procuramos contextualizar as PES, cotejando-as com o modelo de saúde, que ainda parece se caracterizar por elementos disciplinadores e normatizadores. Para tanto, foi importante explicitarmos nossa compreensão da história, cenários e sujeitos das PES, bem como da pluralidade de espaços, tempos e atores/teias de relações: subjetivas, interativas e contextuais.

Desse modo, esse movimento de olhares possibilitou problematizar essas práticas, levantando questões que atravessaram outros campos do saber, e não apenas se reduzindo ao biológico. Esses diferentes olhares dizem respeito às outras maneiras de formular, de interrogar e de conceber as relações entre saber e poder, ou seja, partir da premissa das possibilidades do discurso, das coisas ditas e de sua materialidade. Pois questionar as concepções que se estabelecem historicamente consiste em fervilhar novas/outras possibilidades de compreensão, possibilitando a ultrapassagem das relações que se multiplicam nessas tessituras, deslocamentos de conceitos e a produção de novos significados. 
Práticas Educativas em Saúde: disciplina curricular Bagnato MHS, Missio L, Renovato RD, Bassinello GAH

No entanto, acreditamos que este é um primeiro fio que se desponta neste processo. 0 diálogo com outras disciplinas e a continuidade destas discussões deveriam permear toda trajetória de formação profissional do enfermeiro e enfermeira

\section{REFERÊNCIAS}

1.Bagnato MHS, Renovato RD. Práticas educativas em saúde: um território de saber, poder e produção de identidades. In: Rodrigues RM, Deitos RA, organizadores. Estado, desenvolvimento, democracia e políticas sociais. Cascavel (PR): UNIOESTE/GPPS; 2006.

2.Bagnato MHS. Educação em saúde e cidadania: quais discursos circulam nos espaços educativos? In: Camargo AMF, Mariguela M, organizadores. Cotidiano escolar: emergência e invenção. Piracicaba (SP): Jacintha; 2007.

3.Escosteguy ACD. Cartografias dos estudos culturais: uma versão latino-americana. Belo Horizonte (MG): Autentica; 2001.

4. Costa MV, Silveira RH, Sommer LH. Estudos culturais, educação e pedagogia. Rev Bras Educ 2003 maio/ago; 23: 36-61.

5.Costa MV. Mídia, magistério e política cultural. In: Costa MV, organizadora. Estudos culturais em educação: mídia, arquitetura, brinquedo, biologia, literatura, cinema. Porto Alegre (RS): Ed.da Universidade; 2000.

6.Hall S. A identidade cultural na pós-modernidade. $3^{\mathrm{a}}$ ed. Rio de Janeiro (RJ): DP\&A; 1999.

7.Williams R. Cultura. Tradução de Lólio Lourenço de Oliveira. Rio de Janeiro(RJ): Paz e Terra; 2000.

8.Kruse MHL. Os poderes dos corpos frios: das coisas que ensinam às enfermeiras. Brasília (DF): ABEn; 2004.

9.Oliveira DL, Meyer DEE, Santos LHS, Wilhelms DM. A negociação do sexo seguro na TV: discursos de gênero nas falas de agentes comunitárias de saúde do Programa Saúde da Família de Porto Alegre, Rio Grande do Sul, Brasil. Cad Saude Publica 2004 set/out; 20(5): 1309-318. para que o movimento do diálogo, da construção, da desconstrução, da desnaturalização e da problematização se tornem fundantes para o exercício das práticas educativas em saúde.

10.Renovato RD, Bagnato MHS, Missio L, Murback SESL, Cruz LP, Bassinello GAH. Significados e sentidos de saúde socializados por artefatos culturais: leituras das imagens de advertência nos maços de cigarro. Cienc Saude Coletiva [on-line] 2006 [citado 2 maio 2008]; [aprox 5 telas]. Disponível em: http://www.abrasco.org.br/ cienciaesaudecoletiva/artigos/ artigo int.php?id artigo $=162$.

11.Santos LHS. Biopolíticas de HIV/AIDS no Brasil: uma análise dos anúncios televisivos das campanhas oficiais de prevenção: 19862000. [tese de doutorado]. Porto Alegre (RS): Faculdade de Educação /UFRGS; 2002.

12.Canclini NG. Culturas híbridas: estratégias para entra e sair da Modernidade. $4^{\text {a }}$ ed. São Paulo (SP): Universidade de São Paulo; 2006.

13.Foucault M. História da sexualidade, 1: a vontade de saber. $16^{\mathrm{a}}$ ed. Rio de Janeiro(RJ): Graal; 2005.

14.Ortega F. Da ascese à bio-ascese. In: Rago M, Orlandi LBL, Veiga Neto $A$, organizadores. Imagens de Foucault e Deleuze: ressonâncias nietzschianas. Rio de Janeiro (RJ): DP\&A; 2002.

15. Missio L, Renovato RD, Bagnato MHS, Bassinello GAH. As implicações da educação em saúde como práticas de bio-ascese na constituição do sujeito "autônomo". Anais do $14^{\circ}$ Seminário Nacional de Pesquisa em Enfermagem- SENPE, 2007, Florianópolis (SC), Brasil. Florianópolis (SC): ABEn; 2007. p. 1.

16.Figueiredo MLF, Monteiro CFS, Nunes BMVT, Luz MHBA. Educação em saúde e mulheres idosas: promoção de conquistas políticas, sociais e em saúde. Esc Anna Nery Rev Enferm 2006 dez; 10 (3): 456-66. 